\title{
PENGETAHUAN DAN SIKAP IBU MENYUSUI DENGAN PEMBERIAN ASI SECARA ON DEMAND DI RSB. RESTU MAKASSAR
}

\author{
Knowledge and Attitude of Mother Associated with Giving ASI \\ on Demand in RSB. Makassar Restu \\ Afriani ${ }^{1}$, Wirawati Amin ${ }^{2}$ \\ Jurusan Kebidanan Poltekkes Kemenkes Makassar \\ afriani@poltekkes-mks.ac.id \\ Hp. 081342412307
}

\begin{abstract}
One of the efforts to reduce the Infant Mortality Rate (IMR) is by giving ASI in accordance with the baby's wishes, breastfeeding on demand, where the mother gives her breast milk every time the baby asks and is not based on the hour. It is very important because at first, the baby suckles irregularly, but after a week or two the pattern of breastfeeding is regular. The breastfeeding time for babies is usually two or three hours. And this pattern will not cause problems like the occurrence of dams and so on. Constraints in breastfeeding on demand are problems with the mother and baby. Problems with the mother, for example, the mother feels pain in the nipple while breastfeeding the baby due to the wrong position of breastfeeding and lack of knowledge of the mother about the correct position of breastfeeding. Working mothers can be used as an excuse so that mothers reduce their baby's breastfeeding schedule or even stop breastfeeding so that babies do not get breast milk intake according to their needs. Research will be carried out at RSB. Restu Makassar in the period of May to October 2017. The purpose of this study is to determine the relationship between knowledge and attitudes of breastfeeding mothers with breastfeeding on Demand. This study uses an analytical survey with a "cross sectional study" approach. The focus in this study is the knowledge and attitudes of mothers in breastfeeding on demand. Data analysis used is Chi-Square. The results showed that the respondents' knowledge and attitude had a higher percentage in both (65.3\%) and (72.2\%) categories. From the results of Chi-Square test obtained variables of knowledge and attitudes have a significant effect on breastfeeding on demand with $p$ values of each $p=$ 0.001 and $p=0.000$. The results of this study conclude that good knowledge and attitudes influence on breastfeeding on demand in RSB. Restu Makassar.
\end{abstract}

Keywords: Giving ASI on demand, knowledge and attitude.

\section{ABSTRAK}

Salah satu upaya untuk menurunkan Angka Kematian Bayi (AKB) adalah dengan memberikan ASI sesuai dengan keinginan bayi, pemberian ASI on demand yaitu dimana ibu memberikan ASI nya setiap bayi meminta dan tidak berdasarkan jam. Sangat penting karena pada mulanya, bayi menyusu secara tidak teratur, tetapi setelah satu atau dua minggu pola menyusuinya sudah teratur. Jenjang waktu menyusui pada bayi biasanya dua-tiga jam sekali. Dan pola ini tidak akan menimbulkan masalah seperti terjadinya bendungan dan sebagainya. Kendala dalam pemberian ASI on demand yaitu adanya masalah pada ibu dan bayi. Masalah pada ibu misalnya ibu merasakan nyeri pada puting saat menyusui bayi yg disebabkan posisi menyusui yang salah dan kurangnya pengetahuan ibu tentang posisi menyusui yang benar. Pada ibu bekerja dapat dijadikan alasan sehingga ibu mengurangi jadwal menyusui bayinya atau bahkan menghentikan pemberian ASI sehingga bayi tidak memperoleh asupan ASI sesuai dengan kebutuhannya. Penelitian akan dilaksanakan di RSB. Restu Makassar dalam kurun waktu bulan Mei sampai Oktober 2017. Tujuan Penelitian ini yaitu untuk mengetahui hubungan pengetahuan dan sikap ibu menyusui dengan pemberian ASI secara On Demand. Penelitian ini menggunakan survey analitik dengan pendekatan "cross sectional study". Fokus dalam penelitian ini yaitu pengetahuan dan sikap ibu dalam pemberian ASI secara on demand. Analisis data yang digunakan adalah Chi-Square. Hasil penelitian menunjukkan bahwa pengetahuan dan sikap responden memiliki persentase yang lebih tinggi pada kategori baik $(65,3 \%)$ dan $(72,2 \%)$. Dari hasil uji Chi-Square diperoleh variabel pengetahuan dan sikap memiliki pengaruh yang bermakna terhadap pemberian ASI secara on demand dengan nilai $p$ masing-masing $p=0,001$ dan $p=0,000$. Hasil penelitian ini menyimpulkan bahwa pengetahuan dan sikap yang baik, berpengaruh terhadap pemberian ASI secara on demand di RSB. Restu Makassar.

Kata Kunci: Pemberian ASI secara on demand, pengetahuan dan sikap. 


\section{PENDAHULUAN}

Menyusui adalah suatu proses yang alamiah namun tetap harus dipelajari bagaimana cara menyusui yang baik dan benar, karena menyusui sebenarnya tidak saja memberikan kesempatan kepada bayi untuk tumbuh menjadi manusia yang sehat secara fisik saja tetapi juga lebih cerdas, mempunyai emosional yang stabil, perkembangan spiritual yang baik serta perkembangan sosial yang lebih baik. Air Susu lbu (ASI) adalah makanan bayi yang paling penting terutama pada bulan-bulan pertama kehidupan (Roesli, 2010).

World Health Organization (WHO) mengeluarkan standar pertumbuhan anak yang kemudian diterapkan di seluruh belahan dunia. Isinya adalah menekankan pentingnya pemberian ASI saja kepada bayi sejak lahir sampai usia 6 bulan. Berdasarkan hasil penelitian World Health Organization (WHO) di enam negara berkembang risiko kematian bayi antara usia $9-12$ bulan meningkat $49 \%$ jika bayi tersebut tidak disusui, untuk bayi berusia dibawah dua bulan angka kematian meningkat 48\% (Roesli, 2012).

Salah satu upaya untuk menurunkan Angka Kematian Bayi (AKB) adalah dengan memberikan ASI sesuai dengan keinginan bayi, pemberian ASI on demand yaitu dimana ibu memberikan ASI nya setiap bayi meminta dan tidak berdasarkan jam. Sangat penting karena pada mulanya, bayi menyusu secara tidak teratur, tetapi setelah satu atau dua minggu pola menyusuinya sudah teratur. Jenjang waktu menyusui pada bayi biasanya dua-tiga jam sekali. Dan pola ini tidak akan menimbulkan masalah seperti terjadinya bendungan dan sebagainya (Roesli, 2012).

Kendala dalam pemberian ASI on demand yaitu adanya masalah pada ibu dan bayi. Masalah pada ibu misalnya ibu merasakan nyeri pada putting saat menyusui bayi yg disebabkan posisi menyusui yang salah dan kurangnya pengetahuan ibu tentang posisi menyusui yang benar. Pada ibu bekerja dapat dijadikan alasan sehingga ibu mengurangi jadwal menyusui bayinya atau bahkan menghentikan pemberian ASI sehingga bayi tidak memperoleh asupan ASI sesuai dengan kebutuhannya. Sindrom ASI kurang dimana ibu merasa air susu yang diproduksi kurang yang ditandai dengan bayi sering menangis dan menolak untuk menyusu serta bayi menyusu dengan waktu yang lama, sehingga hal ini akan mendorong sikap ibu untuk memberikan susu formula guna memenuhi kebutuhan nutrisi bayinya (Suradi, 2014).

Penelitian Febriningsih (2013) yang berkaitan dengan pengetahuan dan sikap ibu terhadap pemberian ASI secara on demand menunjukkan bahwa ada hubungan antara pengetahuan dan sikap ibu menyusui terhadap kesulitan dalam memberikan ibu menyusui on demand $(p=0,005)$ dan $(p=$ $0,005)$.

Masalah pada bayi yaitu bayi yang sering menangis hal ini disebabkan karena ASI kurang dan bayi merasa tidak puas, bayi bingung puting (nipple confusion) adalah suatu keadaan yang terjadi karena bayi mendapat susu formula dalam botol berganti-ganti dengan menyusu pada ibu, bayi sakit hal ini jelas akan menghambat proses pemberian ASI pada bayi karena dalam keadaan sakit bayi akan malas menyusu sehingga kebutuhan nutrisinya akan berkurang dan ibu akan mengalami kesulitan dalam memberikan ASI sesuai keinginan bayi (Suradi, 2014).

Tujuan umum penelitian ini adalah Mengetahui hubungan pengetahuan dan sikap ibu menyusui dengan pemberian ASI secara On Demand di RSB. Restu Makassar.

\section{METODE PENELITIAN}

Penelitian ini dilaksanakan di Rumah Sakit Bersalin Restu Makassar. Desain penelitian menggunakan desain cross sectional study. Populasi dalam penelitian ini adalah semua ibu menyusui yang mempunyai bayi usia 0-6 bulan di RSB. Restu Makassar sebanyak 89 orang. Sampel penelitian adalah ibu menyusui yang mempunyai bayi usia 0-6 bulan di RSB. Restu Makassar dalam kurun waktu penelitian dengan teknik Simple random sampling yang berjumlah 72 orang.

Sumber data penelitian adalah data primer yang diperoleh langsung dari ibu menyusui melalui penyebaran kuesioner dan data sekunder yang diperoleh melalui rekam medik. Teknik analisis data yang digunakan adalah analisis univariat dan analisis bivariat dengan menggunakan uji Pearson chi-Square.

\section{HASIL DAN PEMBAHASAN}

Penelitian ini dilaksanakan di Rumah Sakit Bersalin Restu Makassar. Hasil analisis disajikan dalam bentuk tabel yang dilengkapi dengan penjelasan tabel sebagai berikut: 
Tabel 1.Karakteristik responden
pemberian ASI secara On
Demand di RSB. Restu Makassar

\begin{tabular}{lcc}
\hline \multicolumn{1}{c}{ Variabel } & Jumlah (n) & $\begin{array}{c}\text { Persentase } \\
(\%)\end{array}$ \\
\hline Umur (thn) & & \\
$<20$ & 5 & 6,9 \\
$20-35$ & 54 & 75,0 \\
$>35$ & 13 & 18,1 \\
\hline Paritas & & \\
1 & 30 & 41,7 \\
$2-4$ & 39 & 54,2 \\
$\geq 5$ & 3 & 4,2 \\
\hline Pendidikan & & \\
SD & 2 & 2,8 \\
SMP & 3 & 4,2 \\
SMA & 41 & 56,9 \\
PT & 26 & 36,1 \\
\hline Pekerjaan & & \\
Bekerja & 33 & 45,8 \\
Tidak bekerja & 39 & 54,2 \\
& &
\end{tabular}

Sumber : Data Primer RSB. Restu Makassar 2017

Tabel 1 menunjukkan jumlah responden terbanyak pada umur 20-35 tahun $(75,0 \%)$, usia ini adalah usia reproduksi yang baik untuk masa kehamilan, bersalin dan menyusui. Jumlah paritas terbanyak adalah paritas $2-4(54,2 \%)$, hal ini sejalan dengan usia responden yang terbanyak pada usia reproduktif 20-35 tahun. Dari data tingkat pendidikan menunjukkan tingkat pendidikan SMA yang tertinggi yaitu 56,9\% dan paling sedikit adalah di tingkat pendidikan tinggi $(36,1 \%)$ Dari data pekerjaan, mayoritas ibu yang menjadi responden tidak bekerja atau ibu rumah tangga $(54,2 \%)$.

Tabel 2. Distribusi pemberian ASI secara On Demand

$\begin{array}{ccc}\text { Pemberian ASI } & \text { Jumlah } & \text { Persentase } \\ \text { secara On } & (\mathrm{n}) & (\%) \\ \text { Demand } & & \end{array}$

\begin{tabular}{lll}
\hline Ya & 54 & 75,0 \\
Tidak & 18 & 25,0 \\
\hline
\end{tabular}

Sumber : Data Primer RSB. Restu Makassar 2017

Tabel 2 dapat dilihat bahwa jumlah responden yang memberikan ASI secara on demand memiliki persentase yang lebih banyak yaitu sekitar $(75,0 \%)$ dibanding yang tidak memberikan ASI secara on demand (25,0\%).

Tabel 3. Distribusi variabel pengetahuan dan sikap ibu menyusui dengan pemberian ASI secara On Demand

\begin{tabular}{lcc}
\hline Variabel & $\begin{array}{l}\text { Jumlah } \\
(\mathrm{n})\end{array}$ & $\begin{array}{l}\text { Persentase } \\
(\%)\end{array}$ \\
\hline Pengetahuan & & \\
$\quad$ Baik & 47 & 65,3 \\
$\quad$ Kurang & 25 & 34,7 \\
\hline Sikap & & \\
Baik & 53 & 72,2 \\
$\quad$ Kurang & 20 & 27,8 \\
\hline
\end{tabular}

Sumber : Data Primer RSB. Restu Makassar 2017

Tabel 3 dapat dilihat bahwa tabel 3 terlihat bahwa pengetahuan dan sikap responden memiliki persentase yang lebih tinggi pada kategori baik $(65,3 \%)$ dan (72,2\%).

Tabel 4. Hubungan pengetahuan dan sikap ibu menyusui dengan pemberian ASI secara On Demand

\begin{tabular}{|c|c|c|c|}
\hline Variabel & $\begin{array}{c}\text { Peml } \\
\text { seca } \\
\text { dema } \\
\text { Ya }\end{array}$ & $\begin{array}{r}\text { ian ASI } \\
\text { on } \\
\text { Tidak }\end{array}$ & $P^{*}$ \\
\hline $\begin{array}{l}\text { Pengetahuan } \\
\text { Baik } \\
\text { Kurang }\end{array}$ & $\begin{array}{l}37 \\
17 \\
\end{array}$ & $\begin{array}{c}4 \\
14 \\
\end{array}$ & 0,001 \\
\hline $\begin{array}{l}\text { Sikap } \\
\text { Baik } \\
\text { Kurang }\end{array}$ & $\begin{array}{l}35 \\
19\end{array}$ & $\begin{array}{l}2 \\
16\end{array}$ & 0,000 \\
\hline
\end{tabular}

Tabel 4 dapat dilihat bahwa Untuk mengetahui bahwa variabel pengetahuan dan sikap memiliki hubungan yang bermakna dengan pemberian ASI secara on demand, maka dilakukan uji chi-square diperoleh variabel pengetahuan dan sikap memiliki hubungan yang bermakna dengan pemberian ASI secara on demand dengan nilai $p=0,002$ dan $p=0,000$. atau dapat dikatakan bahwa ada hubungan antara pengetahun dan sikap ibu menyusui dengan pemberian ASI secara on demand. 


\section{PEMBAHASAN}

Pemberian ASI secara on demand adalah Pemberian ASI tidak dijadwal sesuai keinginan bayi, dengan menggunakan kedua payudara setiap menyusui secara bergantian, dan istirahat yang cukup. Menyusui adalah proses pemberian Air Susu Ibu (ASI) kepada bayi, dimana bayi memiliki refleks menghisap untuk mendapatkan dan menelan ASI. Menyusui merupakan proses alamiah yang keberhasilannya tidak diperlukan alat-alat khusus dan biaya yang mahal namun membutuhkan kesabaran, waktu, dan pengetahuan tentang menyusui serta dukungan dari lingkungan keluarga terutama suami ( Roesli, 2012).

Menyusui bukan hanya bermanfaat untuk bayi akan tetapi juga memberikan keuntungan dan manfaat bagi ibu terutama dengan menyusui bayi secara ekslusif (Roesli, 2012). Begitu besar manfaat pemberian ASI secara on demand pada bayi, sehingga dipandang perlu untuk dilakukan oleh semua ibu yang melahirkan kepada bayinya. Hal ini sangat ditentukan oleh tingkat pengetahuan dan sikap seorang ibu dalam membangun komitmen untuk memberikan ASI secara on demand.

Pengetahuan tentang pemberian ASI secara on demand didapatkan dari informasi yang berasal dari hasil membaca, mendapat informasi dari orang lain. Dalam hal ini ibu yang mendapatkan pengetahuan yang memadai tentang manfaat dari pemberian ASI secara on demand akan menumbuhkan motivasi untuk melakukan hal tersebut.

Penelitian Febriningsih (2013) yang berkaitan dengan pengetahuan ibu terhadap pemberian ASI secara on demand menunjukkan bahwa ada hubungan antara pengetahuan menyusui kesulitan dalam memberikan ibu menyusui on demand $(p=$ 0,005).

Hasil penelitian ini menjelaskan bahwa jumlah responden dengan pengetahuan $65,3 \%$. Demikian pula hasil analisis data dengan chi-square menunjukkan adanya hubungan bermakna antara pengetahuan ibu yang baik dengan pemberian ASI secara on demand dengan nilai $p=0,001$.

Sikap adalah juga merespon tertutup seseorang terhadap stimulus atau objek tertentu, yang sudah melibatkan faktor pendapat dan emosi yang bersangkutan (senang - tidak senang, setuju - tidak setuju, baik - tidak baik, dan sebagainya). Newcomb, salah seorang ahli psikologi sosial menyatakan bahwa sikap merupakan kesiapan atau kesediaan untuk bertindak, dan bukan merupakan pelaksanaan motif tertentu. Dalam kata lain, fungsi sikap belum merupakan tindakan (reaksi terbuka) atau aktivitas, akan tetapi merupakan faktor predisposisi perilaku (reaksi tertutup) (Notoatmodjo, 2010).

Penelitian Febriningsih (2013) yang berkaitan dengan pengetahuan ibu terhadap pemberian ASI secara on demand menunjukkan bahwa hubungan antara sikap ibu terhadap ibu menyusui dalam kesulitan menyusui on demand $(p=0,001)$.

Hasil penelitian ini menunjukkan bahwa $72,2 \%$ responden menunjukkan sikap baik atau mendukung pemberian ASI secara on demand. Selanjutnya hasil analisis data dengan menggunakan chi-square test menunjukkan ada hubungan yang bermakna sikap ibu dengan pemberian ASI secara on demand dengan nilai $p=0,000$. Hal ini menyimpulkan bahwa sikap dan motivasi dari seorang ibu sangat menentukan pemberian ASI.

\section{KESIMPULAN}

Ada hubungan pengetahuan yang baik dan sikap yang positif pada ibu hamil dengan pemberian ASI secara on demand pada bayi.

\section{SARAN}

Dari hasil penelitian ini disarankan kepada institusi/fasilitas kesehatan untuk lebih meningkatkan edukasi tentang pentingnya pemberian ASI secara on demand pada bayi

\section{REFERENSI}

Cunningham et al. (2013). Obstetri Williams. Jakarta: EGC.

Febriningsih, Trisnawati, Retnowati (2013). Analisis Faktor Penyulit Dalam Pemberian Asi secara On Demand Di Wilayah Kerja Puskesmas Kalimanah Kabupaten Purbalingga Tahun 2013. Jurnal Kebidanan, Unismu Semarang, Vol 2, No 2 (2013)

Febriyanti, I. B., Kunsianah. \& Widiastuti, P. Y. (2016). Hubungan Perilaku Perawatan Payudara Dengan Kelancaran ASI Pada Ibu Menyusui Di Desa Puguh Kecamatan Pengandon Kabupaten 
Kendal. Jurnal IImu Kesehatan, Volume 7: No.1 (2016).

Fikawati, S dan Syafiq, A (2010). Kajian Implementasi dan Kebijakan ASI Esklusif dan Inisiasi Menyusu Dini di Indonesia. Jurnal Makara Kesehatan. Vol.14. No.1.

Gupta, A., Padhich, J. P., Suri, S. (2013). How Global Rates Of Exclusive Breastfeeding For The First 6 Months Be Enhanced. ICAN. Vol. 5 (3.

Hanulan Septiani, Artha Budi, Karbita. (2017). Faktor-faktor yang berhubungan dengan Pemberian ASI Esklusif oleh Ibu Menyusui yang Bekerja sebagai Tenaga Kesehatan. Jurnal IImu Kesehatan Vol. 2. No.2.

Khayati, N; Rachmawati, I. N; Nasution, Y. (2013). Pelaksanaan Manajemen Laktasi oleh Perawat di Rumah Sakit dan Faktor yang Mempengaruhinya. Prosiding PPNI. Jawa Tengah: PPNI, 2013.

Kurniawan, B. (2013). Determinan Keberhasilan Pemberian Air Susu Ibu Eksklusif. Jurnal Kedokteran Brawijaya. Vol. 27 (2013).

Nani, A. S., \& Masruroh. (2016). Hubungan Status Gizi Ibu Dengan Pengeluaran Kolostrum Pada Ibu Nifas Di Wilayah Puskesmas Patebon 01 Kabupaten Kendal. Jurnal IImu Kesehatan, Volume 6: No 2: Page 2 (2016).

Nur Fauzia Asmi, Citra Kesumasari, Abdul Salam (2014). Perilaku Petugas Kesehatan Terhadap Langkah Menuju Keberhasilan Menyusui Di Rsia Pertiwi Kota Makassar. Program Studi IImu Gizi Fakultas Kesehatan Masyarakat Universitas Hasanuddin Makassar (2014).
Priscilla, V., \& Sy, E. (2011). Hubungan Pelaksanaan Menyusui Dini dengan Pemberian ASI Eksklusif di Wilayah Kerja Puskesmas Tanah Garam Kota Solok. Jurnal Kesehatan Masyarakat, Volume 6: No 1 (2011).

Suradi, R. (2014). Pemberian asi eksklusif atau asi saja. http://www. depkes.go.id. Diakses pada tanggal 10 Januari 2017.

Tri Hartatik. 2009. Hubungan Pengetahuan dan Sikap Ibu dengan Pemberian ASI Eksklusif di Kelurahan Gunungpati Kecamatan Gunungpati Kota Semarang tahun 2009. Skripsi. Jurusan IImu Kesehatan Masyarakat, Fakultas IImu Keolahragaan, Universitas Negeri Semarang.

WHO. (2014), Global Health Observatory (Gho): Situation And Trend "Infant Mortaliy”. WHO, 2014 diakses 14 Februri 2016 http://www.who.int/gho/ child health/mortality/neonatal infant.

Wulandari, F. I., Rosita, R., \& Iriani, N. R. (2013). Karakteristik Ibu Menyusui yang Tidak Memberikan ASI Eksklusif di UPT Puskesmas Banyudono I Kabupaten Boyolali. Jurnal Ilmiah Rekam Medis dan Informatika Kesehatan , Volume 3; No 2 (2013).

Yuniyanti, Rofi'ah, Rubiyanti (2016). Efektivitas Kelompok Pendukung Asi (KP-ASI) Eksklusif Terhadap Perilaku Pemberian Asi Eksklusif, Jurnal IImiah Bidan, Vol.II, No.1 (2017). 